\title{
Noticiou o que viu, vacinou quem não viu? Uma análise da cobertura da imprensa capixaba durante a epidemia de febre amarela no Espírito Santo em 2017
}

\author{
Marcio Martins CALIL ${ }^{1}$ \\ Victor Israel GENTILLI ${ }^{2}$
}

Resumo:

Sob a perspectiva do campo da Comunicação e Saúde, este estudo analisou a cobertura jornalística de dois jornais impressos capixabas - A Gazeta e A Tribuna - durante a epidemia de febre amarela no Espírito Santo, entre os meses de janeiro e março de 2017. Utilizando a metodologia da Análise de Conteúdo, a pesquisa concluiu que: a cobertura jornalística apresentou viés alarmista, sem dar a devida distinção entre febre amarela silvestre e urbana, e contribuiu para a procura desordenada aos postos de vacinação; houve conflito discursivo entre os campos jornalístico e da saúde, e entre agentes do próprio campo da saúde; os dois jornais impressos capixabas limitaram-se ao funcional mediador da informação, não se constatando, sob a perspectiva conceitual teórica proposta para esta pesquisa, o papel social do jornalismo de divulgador científico ou de fomentador de debates acerca de políticas públicas de saúde.

Palavras-chave: Jornalismo. Comunicação e Saúde. Risco. Febre Amarela. Epidemia.

\section{Did you report who saw and vaccinated who didn't? An analysis of the Espírito Santo's press coverage during the yellow fever epidemic in Espírito Santo back in 2017}

\begin{abstract}
:
From the perspective of the field of Communication and Health, this study analyzed the journalistic coverage of two newspapers from Espírito Santo - A Gazeta and A Tribuna - during the yellow fever epidemic in Espírito Santo, between January and March of 2017. Using the methodology of Content Analysis, the research concluded that: the press coverage presented an alarmist bias, without the due distinction between wild and urban yellow fever, and contributed to the disorderly demand of vaccination posts; A discursive conflict happened among the journalistic and health fields, and between agents in the health field itself; Espirito Santo's two printed news papers were limited to the functional mediator of information, and, under the theoretical conceptual perspective proposed for this research, the social role of journalism as a scientific disseminator or promoter of debates about public health policies was not verified.
\end{abstract}

Keywords: Journalism. Communication and Health. Risk. Yellow Fever. Epidemic.

\footnotetext{
${ }^{1}$ Doutorando do Instituto de Comunicação e Informação Científica e Tecnológica em Saúde/Fiocruz. Mestre em Comunicação e Territorialidades pela Universidade Federal do Espírito Santo.E-mail: marciomcalil@gmail.com

${ }^{2}$ Doutor em Ciências pela Escola de Comunicação e Artes da Universidade de São Paulo (ECA-USP). Professor titular no Departamento de Comunicação Social da Universidade Federal do Espírito Santo. Docente do Programa de Pós-graduação em Comunicação e Territorialidades (Ufes). E-mail: vgentilli@gmail.com
} 


\section{¿Informó quién vio y vacunó a quién no? Un análisis de la cobertura de prensa de Espírito Santo durante la epidemia de fiebre amarilla en la región en 2017}

Resumen:

Desde la perspectiva del campo de la Comunicación y la Salud, este estudio analizó la cobertura periodística de dos periódicos de Espírito Santo - A Gazeta y A Tribuna - durante la epidemia de fiebre amarilla en Espírito Santo, entre los meses de enero y marzo de 2017. Utilizando la Metodología de Análisis de Contenido, la investigación concluyó que: la cobertura informativa presentó un sesgo alarmista, sin la debida distinción entre fiebre amarilla silvestre y urbana, y contribuyó al registro desordenado de los puestos de vacunación; hubo conflicto discursivo entre el campo periodístico y sanitario, y entre agentes del propio campo sanitario; los dos periódicos impresos de Espírito Santo se limitaron al mediador funcional de la información y, bajo la perspectiva teórica conceptual propuesta para esta investigación, no se encontró el rol social del periodismo como divulgador científico o promotor de debates sobre políticas públicas de salud.

Keywords: Periodismo. Comunicación y Salud. Riesgo. Fiebre amarilla. Epidemia.

\section{Introdução}

As coberturas jornalísticas e a mediação entre saúde e sociedade são um processo complexo, com narrativas permeadas por disputas entre os campos do jornalismo e da saúde. Essas disputas e tensões ocorrem frequentemente nas abordagens dos meios de comunicação de massa sobre saúde em aspectos como fatores de risco, mas também como promotora de qualidade e hábitos saudáveis: alimentação, prolongamento da vida, novos medicamentos e tratamentos, avanços nas tecnologias e diagnósticos cada vez mais precoces de doenças, aconselhamentos sobre comportamento, estética e padrões de beleza (OLIVEIRA, 2014).

De modo geral, é importante frisar, a gestão do risco em saúde está majoritariamente fincada na lógica do risco, orientando-se pela disciplinarização de comportamentos e corpos. E essa tem sido a perspectiva da mídia, em seu esforço de ser "espelho" da realidade (MALINVERNI, 2017). Tal esforço vem marcando a cobertura midiática da saúde desde a criação, em 1978, do primeiro suplemento jornalístico especializado por um veículo de comunicação de massa, o jornal norte-americano The New York Times. De lá para cá, o interesse da mídia ocidental pelo tema vem crescendo exponencialmente; hoje, o discurso midiático da saúde é onipresente no cotidiano das populações de diferentes países, inclusive a brasileira (TABAKMAN, 2013).

Uma das abordagens jornalísticas sobre saúde diz respeito ao objeto desta pesquisa, que são as construções narrativas das coberturas jornalísticas de doenças epidêmicas no Brasil. Nas rotinas de produção das notícias (newsmaking) nas redações de jornais impressos, as pautas sobre saúde/doença, apesar do notório crescimento, não raro ficam circunscritas às 
editorias específicas sobre o tema, às colunas especializadas ou a cadernos especiais. Quando ganha destaque em editorias e espaço de maior visibilidade, como Cidades e em chamadas de capa, a temática frequentemente está relacionada a riscos de morbidade e mortalidade em consequência de surtos/epidemias, e, em menor escala, por notícias sobre curas ou novas tecnologias para tratamentos (OLIVEIRA, 2014; WAISBORD, 2010).

Doenças epidêmicas, que fora da sazonalidade das ocorrências ficam à margem dos critérios de noticiabilidade midiáticos, ganham destaque e entram no fluxo intenso de produção das notícias, no chamado ciclo mediático epidêmico (WAISBORD, 2010), que pode perdurar por semanas. Seleção, exposição, atualização, acumulação, relevância e saliência passam, então, como apontam protocolarmente os manuais e teorias da comunicação, a fazer parte do repertório dos gatekeepers que comandam as redações (HOHLFELDT; MARTINO; FRANÇA, 2001; ENTMAN, 1993). Nesse contexto, surge a problemática deste estudo, que é a construção da narrativa midiática das epidemias na atualidade.

Sob a perspectiva do campo da Comunicação e Saúde, o objetivo desta pesquisa foi analisar o conteúdo da cobertura jornalística dos jornais impressos capixabas A Gazeta e $A$ Tribuna, durante a epidemia da febre amarela no Espírito Santo, entre os meses de janeiro e março de 2017, investigando se houve viés alarmista na construção da narrativa midiática, contribuindo para o aumento desordenado na procura e nas filas nos postos de vacinação do Estado. E ainda, se houve conflitos discursivos entre o conteúdo jornalístico e os interlocutores da saúde, amplificando uma sensação de risco e insegurança à saúde na população.

\section{Embasamentos teóricos da pesquisa}

Quatro pressupostos teóricos perpassaram o desenvolvimento e análise deste estudo: a) o papel do jornalismo como agente social educador, preventivo e divulgador da ciência (saúde); b) a midiatização do risco de doenças epidêmicas; c) a produção da notícia (enquadramento) e d) as tensões discursivas entre os campos do jornalismo e da saúde.

Uma das premissas que norteiam as pesquisas na área da divulgação da ciência, tecnologia e saúde em sua interface com a comunicação jornalística é a de que o direito à informação e à comunicação é indissociável dos demais direitos fundamentais, principalmente o direito à saúde. No campo da Comunicação e Saúde, incorporar novos atores sociais jornalistas e pesquisadores - articulando e refletindo sobre estratégias para comunicar e 
divulgar o conhecimento da ciência e da saúde é pensar de forma democrática e cidadã, contribuindo para a construção das políticas públicas do Sistema Único de Saúde (SUS), especialmente em um momento de retrocesso de conquistas sociais, retração orçamentária e privatização acelerada deste setor pelo qual o país atravessa.

Pesquisas acadêmicas demonstram que a mídia jornalística, concomitante à função precípua de informar, cada vez mais assume protagonismo de influente ator social educador, preventivo e divulgador, sendo, no campo da saúde, parte fundamental do processo de determinação social. Autores como Castelfranchi (2010), Hansen (2009) e Peters (2005) propõem reflexões sobre o papel da mídia contribuindo para a divulgação da ciência, e a saúde em particular, não somente como um direito, mas como um dever social, uma ação democrática.

Importante ressalvar que a perspectiva desta pesquisa sobre os conceitos de comunicação/divulgação científica procura fugir de uma possível "armadilha" conceitual de um viés positivista instrumentalista, no tocante ao papel da imprensa auxiliando o cidadão na tomada de decisão diária sobre o tema saúde, sem o necessário dialogismo entre interlocutores. Isto se faz necessário, pois o posicionamento deste trabalho é de crítica ao racionalismo moderno, à primazia do individualismo e a responsabilização do cidadão por sua própria saúde, eximindo o Estado da sua função precípua e excluindo determinantes socioeconômicos culturais e ambientais (CASTIEL; ÁLVAREZ-DARDET DIAZ, 2007).

Nesse contexto, a pesquisa se apropria da visão sobre a lógica do risco epidemiológico e a consequente cobertura midiática dos riscos à saúde como processo de construção histórica dos (já superados) modelos e pensamentos biomédicos modernos que associam o estado de saúde à ausência de doença (CZERESNIA, 2013). Contexto que contribui para a individualização crescente na sociedade contemporânea, influenciando a decisão pela procura por um especialista da saúde ou pelo serviço público que se dá muitas vezes após informação recebida ou "aconselhada” pela indústria midiática jornalística (LERNER, 2014).

A maneira como a imprensa constrói e enquadra a mensagem é fundamental para a aprovação da opinião pública, e o conceito de enquadramento é componente constitutivo na análise deste estudo. Entman (1993) afirma que o enquadramento envolve seleção e saliência, definindo saliência como uma ação a tornar uma informação, além de perceptível, também significativa e memorável para o receptor. Em relação à metodologia aplicada a este estudo, o autor sugere que a teoria do enquadramento pode ajudar na pesquisa empírica, principalmente 
na identificação e diferenciação das palavras e enunciados, de forma negativa ou positiva, que se apresentam mais salientes e influentes no texto.

Sobre as tensões discursivas presentes em textos jornalísticos, Lerner $(2014 ; 2015)$ fala em tensionamento na polifonia das vozes, quando se convocam outros atores sociais para a cena discursiva. Nesse sentido, são necessárias reflexões a respeito dos mecanismos da comunicação jornalística dos temas da ciência e as consequentes tensões entre os campos do jornalismo e o da ciência (saúde), e internamente aos próprios campos. Para esta pesquisa, tratamos campo sob a perspectiva de Bourdieu $(1989 ; 2004)$ em relação ao seu grau de autonomia e heteronomia, da capacidade de cada campo refratar ou retraduzir pressões externas, e de ser influenciado por elas. Neste caso, os campos do jornalismo e o da saúde, e o que o autor aborda sobre sistemas simbólicos e acumulação do poder simbólico, sob o viés da comunicação.

\section{Metodologia}

Para os pressupostos teóricos, objetivos e proposições deste estudo, foi realizada uma pesquisa de abordagem quantitativa e qualitativa, utilizando a metodologia da Análise de Conteúdo (AC), sob a perspectiva de Bardin (2004). Como corpus de pesquisa, foram delimitadas as edições da cobertura jornalística dos jornais impressos capixabas, A Gazeta e $A$ Tribuna, durante a epidemia de febre amarela no Espírito Santo, do dia $1^{\circ}$ de janeiro ao dia 31 de março de 2017. O corpus construído foi possível graças às parcerias com o Observatório da Mídia: direitos humanos, políticas, sistemas e transparência, vinculado ao Programa de Pós-Graduação em Comunicação e Territorialidades; e com o Observatório de Saúde da Mídia - Regional Espírito Santo (OSM-ES), vinculado ao Programa de Pós-Graduação em Saúde Coletiva (PPGSC), ambos da Universidade Federal do Espírito Santo (UFES). Para a análise do corpus, foram extraídas apenas as páginas das publicações contendo a palavrachave "febre amarela", no período de $1^{\circ}$ de janeiro de 2017 a 31 de março de 2017, por meio do aplicativo PDF-XChange. Ao final, o termo "febre amarela" foi localizado em 71 edições do jornal A Gazeta $(A G)$ e em 74 edições de A Tribuna (AT), no período do recorte temporal.

Para a proposta metodológica de levantamento e análise quantitativa e qualitativa do material empírico, foi utilizado o software de processamento de dados Atlas.ti 7 (versão: 7.5.16), que permite extrair, categorizar e interligar segmentos de dados de uma grande variedade e volume de documentos de diversas origens, auxiliando a interface das etapas de descrição, inferência e interpretação da Análise de Conteúdo. E para a classificação e 
codificação como unidades de registro, lançou-se mão do auxílio do protocolo de pesquisa adotado pelo Observatório de Saúde da Mídia-Regional ES, adaptando-o para este estudo.

A priori, para a codificação desta pesquisa foram definidas as seguintes variáveis de classificação do conteúdo do corpus como unidades de registro: Editoria; Chamada de Capa (alta ou baixa); Chamada de Página e Elementos de Edição (infográfico, foto de capa, foto no alto da página, charge). Foram também definidas as seguintes categorias de análise como unidades de contexto: Prevenção/Educação; Risco/Alarmismo; Conflito Discursivo; além da categoria Tipo de Febre Amarela (silvestre, urbana, silvestre e urbana, urbana desde 1942). Posteriormente, foram criados mais dois códigos: Artigo de Especialista e Vacinação Suspensa.

O software Atlas.ti organizou os Documentos Primários no formato PDF, na sequência de P1 a P145, seguindo a ordem cronológica das datas das edições, sendo: de P1 a P71 os documentos PDF referentes ao jornal A Gazeta; e de P72 a P145 referentes ao jornal $A$ Tribuna. A Figura 1 mostra a interface gráfica de análise do Atlas.ti, no caso referente às edições do dia 19 de janeiro de 2017 de A Gazeta (P11) e A Tribuna (P77), ilustrando alguns dos componentes citados disponíveis no software.

Figura 1 - Interface gráfica de análise do Atlas.ti (versão: 7.5.16)

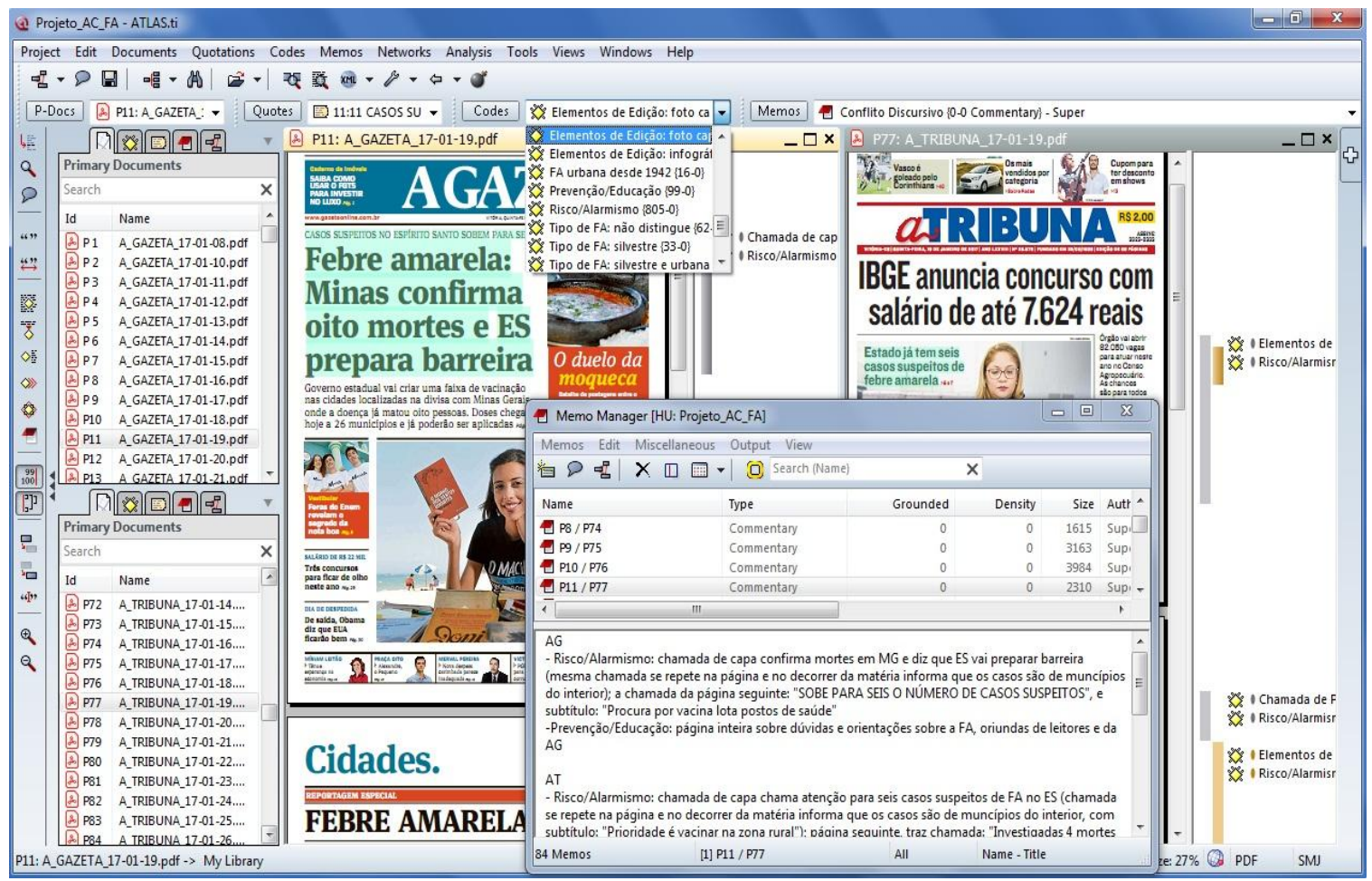

Fonte: os autores. 


\section{Resultados e discussão}

No início da cobertura jornalística de $A G$ e $A T$, em janeiro de 2017, as principais informações vigentes no portal do Ministério da Saúde (MS), que balizaram esta pesquisa, sobre a febre amarela eram:

- Não há casos de febre amarela urbana no país desde 1942 (MS, 2017).

- Para pessoas com mais de 60 anos, o médico deve avaliar os riscos (MS, 2017).

- Contraindicação de vacinação para gestantes e mulheres amamentando crianças de até 6 meses. Em situação de surto, o médico tem que avaliar (MS, 2017).

- Contraindicação de vacinação para pacientes com imunodepressão de qualquer tipo, como portadores do vírus HIV ou que estejam em tratamento com drogas como corticoide e quimioterapia (MS, 2017).

- Validade da vacina: o Ministério da Saúde recomendava uma dose de reforço após dez anos, para crianças e adultos, sendo que adotava um protocolo para crianças de primeira dose aos nove meses e a segunda aos quatro anos de idade. Já a Organização Mundial da Saúde (OMS) dizia que apenas uma dose era suficiente para imunizar contra a doença.

- Se fosse viajar para áreas de risco, tomar a vacina dez dias antes.

- O Espírito Santo não era área de risco.

A Figura 2 é um print do infográfico explicativo sobre transmissão, vetores e ciclos de transmissão (silvestre e urbano) da febre amarela, reproduzido do portal do Ministério da Saúde (MS), com acesso em 15 de janeiro de 2020. 
Figura 2 - Infográfico sobre a transmissão da febre amarela.

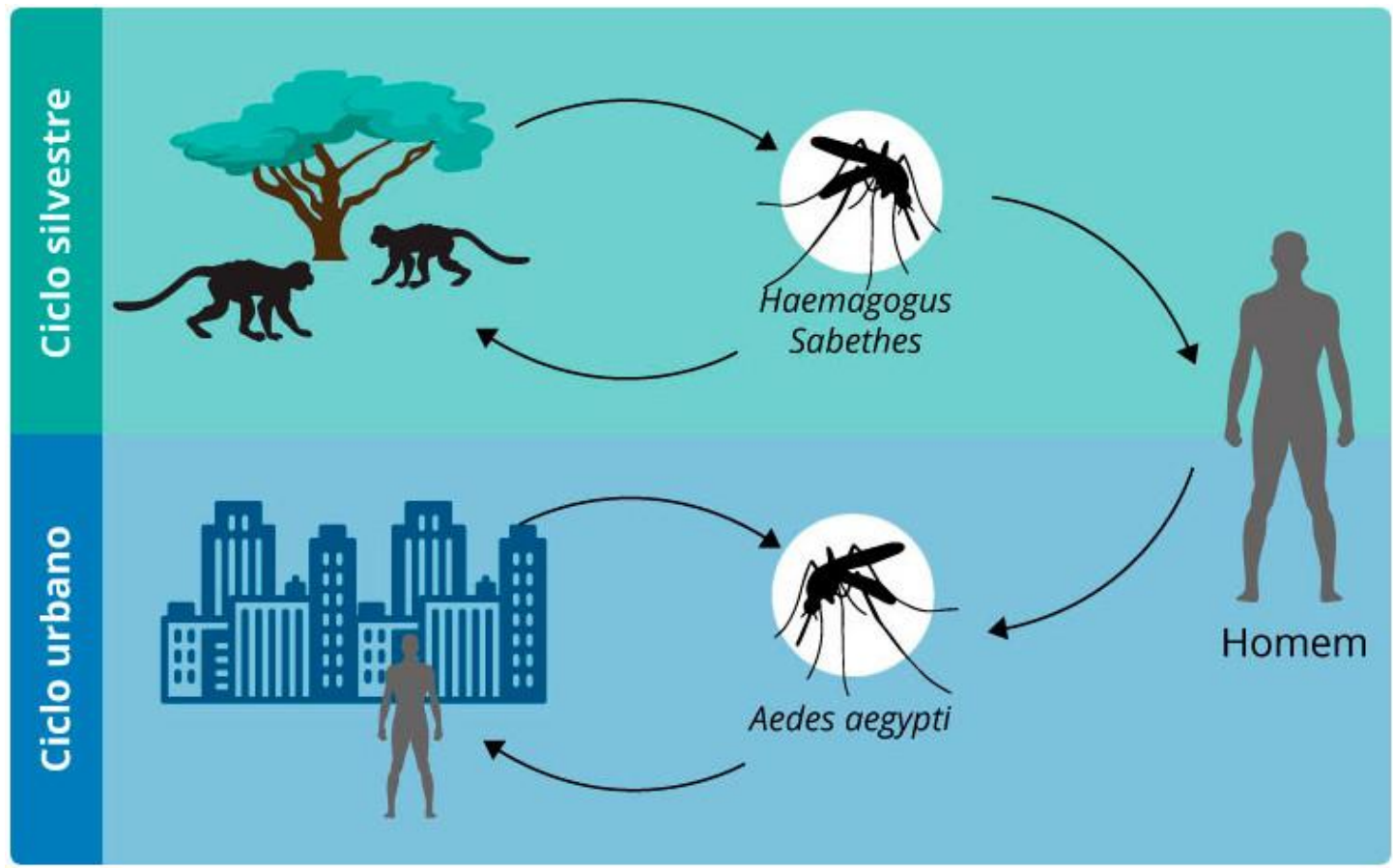

A pessoa apresenta os sintomas iniciais da febre amarela de 3 a 6 dias após ter sido infectada.

IMPORTANTE: O ciclo da doença atualmente é silvestre, com transmissão por meio de vetor (mosquitos dos gêneros Haemagogus e Sabethes no ambiente silvestre). $O$ último caso de febre amarela urbana foi registrado no Brasil em 1942 e todos os casos confirmados desde então decorrem do ciclo silvestre de transmissão.

Fonte: Ministério da Saúde (2020).

Essas informações e, naturalmente, o importante dado epidemiológico em destaque sobre a febre amarela urbana eram os mesmos em 2017, período da cobertura jornalística do corpus. A criação da unidade de codificação Tipos de FA (silvestre, urbana, silvestre e urbana, urbana desde 1942) possibilitou o acompanhamento ao longo desta análise de conteúdo da narrativa jornalística sobre a que tipo de febre amarela - silvestre ou urbana - se referiam os jornais em relação às notificações, e os consequentes desdobramentos e implicações envolvendo as proposições de pesquisa.

A investigação permitiu constatar que a palavra "silvestre" não apareceu em nenhuma das 83 chamadas de capa ${ }^{3}$ e em nenhuma das 268 chamadas de páginas de $A G$ e $A T$, ao longo do recorte temporal desta pesquisa. Este dado é significativo, pois o fato de, durante três meses, o noticiário destacar e massificar apenas o termo "febre amarela", não deixou claro

\footnotetext{
${ }^{3}$ Houve uma localização da palavra "silvestre" apenas no elemento gráfico conhecido como "subtítulo" ou "linha-fina", frase ou texto menor que fica abaixo do título (chamada), na capa da edição do dia 24 de janeiro de 2017, de $A G$ (P16).
} 
para os leitores que a epidemia se tratava da febre amarela do tipo silvestre. A omissão da palavra "silvestre" foi uma não informação.

A Figura 3 mostra a nuvem de palavras formada pelas chamadas das páginas e capas do corpus. Do total de palavras ocorridas, as mais frequentes são: febre (112); amarela (101); vacina (81); estado (74); vacinação (59); vitória (51); doses (47); doença (39); postos (39); morte (38); mortes (34); macacos (33); suspeita (32); vacinar (28).

Figura 3 - Nuvem de palavras das chamadas de capa e página de A Gazeta e A Tribuna

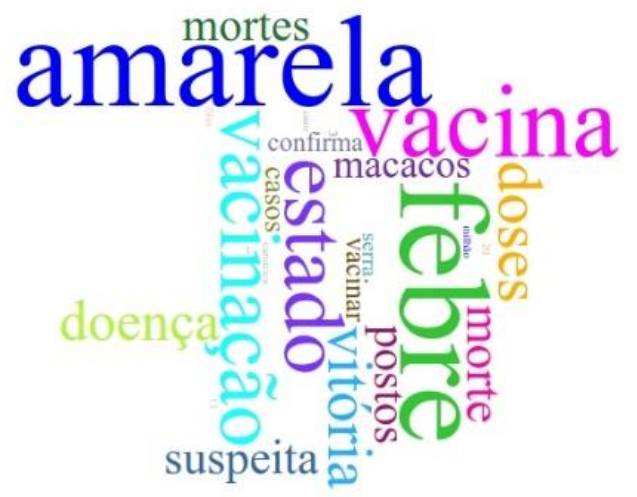

Fonte: os autores.

A contextualização do Tipo de FA é linha condutora transversal para os quatro pressupostos teóricos e as proposições desta pesquisa. Desde o início da cobertura, e ao longo do recorte temporal, os interlocutores da saúde (especialistas, pesquisadores, peritos e autoridades e gestores públicos sanitários) afirmavam que não havia motivo para pânico e correria aos postos de vacinação para se imunizarem contra a febre amarela, enfatizando esse posicionamento em relação aos moradores das áreas urbanas da Grande Vitória ${ }^{4}$. O que todos concordavam era em relação à vacinação da população dos municípios limítrofes com Minas Gerais e, posteriormente, os que registravam casos suspeitos em função de macacos mortos encontrados, formando o que a Secretaria de Estado da Saúde (SESA) chamou de barreira vacinal (ou cautelar), como estratégia de prevenção da proliferação do vírus.

Logo na primeira edição em que $A G$ (dia 13/01/17 - P5) apresentou chamada de capa e de página - após quatro edições apenas com menções sobre a FA em matérias na seção especial "Notícias de Minas", temporária na editoria de Cidades - o jornal entrevistou uma

\footnotetext{
4 A região metropolitana da Grande Vitória é composta por sete municípios: Vitória, Vila Velha, Serra, Cariacica, Viana, Guarapari e Fundão.

${ }^{5}$ A primeira notícia sobre febre amarela no noticiário capixaba foi uma pequena nota (no jargão jornalístico impresso também conhecido por "foguete"), no dia 8 de janeiro daquele ano, em A Gazeta, sobre mortes
} 
infectologista responsável pelo programa de imunização da SESA, que explicou a diferença entre FA silvestre e urbana, as maneiras de transmissão, prevenção e sintomas da doença, todas as orientações reforçadas por meio de um box de entrevista na página, com o título "Em Alerta". Nessa entrevista, a especialista já ressaltava que "A febre amarela silvestre são esses casos mais recentes, porque a febre amarela urbana, que é dentro da cidade, a gente já não tem no Brasil desde 1942” (EM ALERTA, 2017, p. 11).

Situação semelhante à $A T$, que na primeira edição em que noticiou a FA (dia 14/01/17 - P72) publicou o infográfico também explicando a diferença entre FA urbana e silvestre, sintomas, formas de se prevenir e, assim como $A G$, entrevistou um infectologista que declarou não haver razão para pânico no estado e que não havia "registro de casos em áreas urbanas onde o vetor é o mosquito Aedes aegypti, o mesmo da dengue - desde 1942" ([Entrevista], 2017, p. 2). A matéria também informava que o ES era considerado região fora da área de risco. Daí em diante, o que se constatou durante a análise de conteúdo foi uma construção narrativa com viés alarmista em torno da urgência pela vacinação em massa de toda a população do ES, defendida também por meio de editoriais.

Waisbord (2010) aborda a questão da potencialização da sensação de risco na construção das notícias sobre epidemias, e se refere a três fases do que ele chama de ciclo midiático epidêmico: 1) ausência ou presença limitada nas seções especializadas; 2) intensa cobertura e priorização durante o ciclo noticioso epidêmico; e 3) retorno à cobertura mínima. Das primeiras notícias restritas à seção Notícias de MG, em $A G$, entre os dias 8 e 12 de janeiro, sobre casos de FA no estado mineiro, a construção narrativa do Risco/Alarmismo foi se configurando por meio da massiva quantidade de chamadas de capa $(A G=39 ; A T=44)$ e de página $(\mathrm{AG}=132 ; \mathrm{AT}=136)$, e fotografias de capa $(\mathrm{AG}=9 ; \mathrm{AT}=20)$ e fotografias do alto da página ( $\mathrm{AG}=117 ; \mathrm{AT}=127$ ), ao longo das 90 edições do recorte temporal, em sua maioria em torno do contexto vacinação e postos de vacinação,

As primeiras chamadas de capa de $A G$, no dia 13 de janeiro de 2017 - "Risco de febre amarela no Espírito Santo” (RISCO..., 2017, p. 1) - e de AT, no dia 14 de janeiro de 2017 "Surto de febre amarela em Minas deixa Espírito Santo em alerta" (SURTO..., 2017, p. 1) - já carregavam as questões abordadas sobre uma amplificação do alarmismo e a não especificação da FA silvestre, reforçados pelo fato de que, até então, os casos notificados no ES e publicados se referiam a suspeitas e notificações somente de macacos mortos no interior do Estado, característico dos vetores e hospedeiro envolvidos no ciclo silvestre da doença. 
Já as primeiras publicações sobre investigação de possível transmissão para humanos no Espírito Santo acontecem em $A G$ e em $A T$, no dia 16 de janeiro de 2017. Tratava-se de dois pacientes internados no interior do ES com sintomas similares aos da FA, como febre alta e vômitos, e que também foram as principais chamadas das capas (as manchetes principais) das edições dos dois jornais: "Casos suspeitos de febre amarela no Estado deixam Saúde em alerta" (CASOS..., 2017, p. 1); e "Estado já tem dois pacientes com suspeita de febre amarela" (ESTADO..., 2017, p. 1). As edições do dia seguinte, 17 de janeiro de 2017, de $A G$ e $A T$ já trouxeram como chamadas de capa e fotografia na capa (esta, em $A G$ ) o contexto que iria marcar a cobertura sobre filas, confusão e procura por vacina, mas com imagens e falas de moradores nos postos de saúde da Grande Vitória, potencializada pela notícia de que um macaco morto fora encontrado na capital Vitória, em um bairro de classe econômica alta. O número de páginas que mencionavam a FA nos dois jornais, que era de no máximo quatro, nesse dia aumentou para oito páginas em $A G$ e para seis em $A T$, situação que se repetiu no dia seguinte.

Em relação ao Conflito Discursivo entre os campos do jornalismo e dos especialistas da saúde, principalmente quanto à questão da cobertura vacinal, cabe registrar uma entrevista do então presidente da Sociedade Brasileira de Virologia (SBV) concedida ao jornal $O$ Globo, repercutida tanto em $A G$ quanto em $A T$, no dia 21 de janeiro de 2017. Em meio a uma série de notícias envolvendo aumento de casos ainda suspeitos de FA no interior; anúncio de chegada de vacinas ao Estado para atender a estratégia defendida pelas autoridades de saúde de vacinação nos municípios capixabas limítrofes com MG (barreira de vacinação), mas com bastantes fotos de filas nos postos da Grande Vitória, $A G$ e $A T$ dão destaque a uma fala específica do presidente da SBV: "Espírito Santo é o Estado mais vulnerável à doença", inclusive sendo chamada de página em $A G$ (ESPÍRITO..., 2017, p. 4).

Esta frase é retirada de um contexto em que o presidente da SBV diz:

O Espírito Santo é o mais vulnerável do Brasil para ter casos. A cobertura vacinal é muito baixa, principalmente na região próxima à divisa com Minas. Se é que existe alguma cobertura vacinal. Para o vírus não existem fronteiras. É tudo uma mata só. Então o risco de a doença chegar a cidades e se espalhar é maior. Se uma pessoa adoecer e for para a cidade, outras pessoas estarão expostas (MENDONÇA, 2017, p. 4).

Após a chamada sensacionalista, $A G$ procura cumprir o papel jornalístico de ouvir e publicar as opiniões de especialistas do Espírito Santo a respeito dessa entrevista. Eles reconheciam os cuidados e monitoramento com os casos que surgiam, mas sustentaram o 
posicionamento de não haver razão para pânico:

Uma coisa é estarmos desprotegidos de uma vacinação sistemática em relação às áreas de risco, como na fronteira com Minas e onde há mais densidade de Mata Atlântica. Se tivéssemos uma vacinação estruturada permanentemente nessas áreas estaríamos mais tranquilos. Mas isso não significa que temos que entrar em pânico e achar que a população de todas as áreas do Estado deve estar vacinada - infectologista 1 (MENDONÇA, 2017, p. 4).

Um segundo infectologista entrevistado também não indicava a vacinação em massa naquele momento: "A prioridade é para quem vai para regiões de mata. Primeiro, porque a população da cidade não está ameaçada e, segundo, porque a vacina tem suas contraindicações” (MENDONÇA, 2017, p. 4). O secretário de Estado da Saúde garantia: “O Espírito Santo não é considerado área de recomendação de vacinação. Não temos nenhum caso confirmado em macaco nem em humanos. Esta medida de vacinar os municípios próximos a Minas Gerais é fazer um bloqueio. É uma medida cautelar" (MENDONÇA, 2017, p. 4).

Opiniões e falas conflitantes no próprio campo da saúde, que, baseado na visão de Bourdieu (2004), circunscreve um microcosmo dotado de leis próprias, com seu grau de autonomia, em que os agentes e instituições, nesse caso os da saúde, se apresentam em relações de forças e dominação e disputa concorrencial pelo reconhecimento de competência e legitimidade ao lugar de fala, o capital simbólico: "Os agentes sociais estão inseridos na estrutura e em posições que dependem do seu capital e desenvolvem estratégias que dependem, elas próprias, em grande parte, dessas posições, nos limites das suas disposições" (BOURDIEU, 2004, p. 29).

Os conflitos internos são no campo da saúde, mas são potencializados pelo campo do jornalismo. No contexto macrocósmico dos campos de Bourdieu (1989), na relação de forças envolvidas entre agentes de campos diferentes, o jornalismo exerce uma forma de dominação ao construir o seu próprio espaço de jogo, baseada em arbítrios e impondo normas e a retórica da "objetividade":

As estratégias discursivas dos diferentes atores, e em especial os efeitos retóricos que têm em vista produzir uma fachada de objetividade, dependerão das relações de forças simbólicas entre os campos e dos trunfos que a pertença a esses campos confere aos diferentes participantes [...] (BOURDIEU, 1989, p. 56). 
Apesar de todas as notificações, dados e estatísticas se referirem aos casos que vinham acontecendo nos municípios do interior do Estado, a concentração e repercussão das chamadas, fotos e infográficos dos jornais continuavam sendo a região da Grande Vitória, ao ponto de o secretário do estado da saúde dar a seguinte declaração: "O maior problema que estamos tendo hoje é acalmar a população da Grande Vitória. Estamos tentando mas não estamos conseguindo" (DIAS; CHAGAS; SÁ, 2017, p. 4).

Waisbord (2010) fala que, dentro do ciclo midiático epidêmico, a segunda fase de intensa cobertura jornalística de epidemias é caracterizada pela expansão de casos que ultrapassam fronteiras geográficas e sociais. No Espírito Santo, a questão geográfica era evidente por conta da progressão dos casos provenientes de Minas Gerais, e não é possível inferir algo sobre as fronteiras sociais por meio da metodologia aplicada a esta pesquisa. Contudo, dentro dos critérios de valor-notícia, Wolf (2005) menciona proximidade geográfica e nível hierárquico dos indivíduos envolvidos no acontecimento noticiável, além do aumento da probabilidade do acontecimento se tornar notícia se interessar a pessoas de elite.

O sensacionalismo é um dos elementos utilizados no jornalismo contemporâneo, e as maiores vendas e circulação dos exemplares de A Gazeta e A Tribuna se davam na Grande Vitória, região de maior concentração de renda do estado. A ênfase na repercussão da cobertura jornalística nos municípios da Grande Vitória pode ser interpretada sob a perspectiva dos critérios de valor-notícia, especialmente pela proximidade geográfica e possibilidade de a doença alcançar os moradores dos bairros mais ricos dessa região (amplificada pelo noticiário).

Como já evidenciado e enfatizado, os casos suspeitos e posteriormente confirmados de febre amarela, inclusive os óbitos que vieram a ocorrer, foram todos da febre amarela silvestre. O momento era de os jornais destacarem, sim, as preocupações e recomendações preventivas para conter a proliferação da doença, mas com ênfase nas ações e medidas voltadas inicialmente para os municípios limítrofes com Minas Gerais e depois também para os municípios que notificavam casos suspeitos ou confirmados, formando a chamada barreira vacinal, inserida na estratégia cautelar defendida pelas autoridades públicas da saúde do estado. 
Até a paralisação da vacinação nos postos de saúde por conta da greve da polícia militar do Espírito Santo ${ }^{6}$, no dia 06 de fevereiro de 2017, a barreira vacinal era formada por 60 municípios, incluindo dois da região da Grande Vitória - Cariacica e Fundão, por conta de relatos de macacos mortos na zona rural - e as estatísticas da febre amarela no Espírito Santo apontavam quatro mortes confirmadas pela SESA, todas no interior do estado, e nove sob investigação. A tônica da narrativa jornalística se mantinha em torno da necessidade premente da vacinação em massa de toda a população capixaba e dos pedidos de mais doses da vacina pelo Governo do Estado junto ao Governo Federal, amplificada pelas matérias envolvendo as mortes e adoecimentos por causa da FA, com fotos das vítimas e depoimentos de familiares, notícias sobre tentativa de furto de vacinas em postos de saúde, fechamentos de parques à visitação como medida de prevenção e casos de macacos encontrados mortos.

Em contrapartida, prosseguem os conflitos discursivos, e na edição de $A T$, do dia 27 de janeiro, o infectologista e coordenador do Comitê de Medicina do Viajante da Sociedade Brasileira de Infectologia alerta que uma eventual vacinação em massa seria uma medida arriscada, porque a vacina (feita do vírus vivo atenuado) tem efeitos colaterais graves e, segundo o infectologista, "pode produzir a doença que se quer evitar." Na mesma página de $A T$, uma pesquisadora da Fiocruz afirma não haver naquele momento risco de FA urbana:

As duas espécies transmissoras (Haemagogus e Sabethes) não vivem na área urbana, só silvestre. Já tivemos febre amarela urbana no início do século XX no Brasil. Mas hoje não há risco de o mosquito Aedes aegypti, o da dengue, transmitir febre amarela. As espécies se adaptam. Ele já foi um mosquito silvestre, mas hoje não é mais, é urbano" (AVANÇO, 2017, p. 5).

E, no dia 01 de fevereiro, o especialista e diretor do Instituto Evandro Chagas, diz, em entrevista para $A G$ e $A T$, que o "risco de a doença chegar à Grande Vitória é mínimo. [...] que não há risco de a febre amarela se tornar urbana porque é preciso uma infestação de Aedes aegypti maior do que a quantidade que há no Brasil e no Espírito Santo" (FEBRE, 2017, p. 3).

Essa visada retroalimentadora entre os contextos Risco/Alarmismo e Conflito Discursivo continua acompanhando a cobertura jornalística de $A G$ e $A T$ por toda a análise do corpus, passando pelo quase total sumiço da pauta durante os vinte dias da crise da segurança pública no estado, em fevereiro, voltando a repercutir após esse período, especialmente no

\footnotetext{
${ }^{6}$ Crise na segurança pública do ES, iniciada no dia 04/02 com protestos de familiares de policiais militares em frente a quartéis, reivindicando reajustes salariais, impedindo a saída das viaturas. Durante a crise, que terminou no dia 24/02 e teve a intervenção da Força de Segurança Nacional, o estado contabilizou cerca de 150 mortes, além de assaltos, arrombamentos em lojas, arrastões, fatos que provocaram fechamento do comércio e cancelamento das atividades em escolas, faculdades e órgãos públicos.
} 
tocante à angulação do noticiário para os mutirões de vacinação na Grande Vitória e as metas de se imunizar toda a população do ES. A Organização Mundial da Saúde divulgando em seu site que o estado é considerado área de risco para os viajantes, exceto a região litorânea, que abrange a Grande Vitória. Retorno de destaque e alarmismo, logo no primeiro dia de março, com a divulgação da suspeita da possibilidade da primeira morte por FA na capital Vitória, mas descartada na mesma semana. E, por fim, gradativamente, diminuindo o espaço ao longo do mês de março, alcançando a terceira fase do ciclo midiático epidêmico de Waisbord (2010, p. 96) de "retorno à cobertura mínima".

Sob o contexto da Educação/Prevenção/Divulgação Científica, a pesquisa apontou que houve apenas duas Chamadas de Capa (do total de 83) e 23 Chamadas de Página, menos de $10 \%$ do total (268) do corpus. Uma perspectiva de divulgação da ciência ressaltada por Castelfranchi (2010), que procura destacar a participação social de vários segmentos na avaliação e gestão da ciência contemporânea e o papel estratégico da mídia nessa divulgação e comunicação com o público que ele denomina não-especialistas. Este papel da mídia tanto na divulgação científica quanto no desenvolvimento da cidadania ressaltado por Caldas (2011, p. 26), que conclama para que essa "ação transformadora seja um passo natural à formação de uma consciência individual e coletiva. Desvelar o mundo científico construído pela mídia implica em ajudar as pessoas a encontrarem um sentido nas aparências para a formação plena da cidadania".

\section{Considerações finais}

Não obstante a epidemia de febre amarela em 2017 ter sido uma das mais graves no país, alcançando a região da Mata Atlântica, na costa leste brasileira, o portal do Ministério da Saúde, em janeiro de 2020, ressaltava que “toda esta expansão da circulação do vírus está associada à ocorrência do ciclo silvestre da doença, não havendo nenhum indício da sua urbanização". Em março de 2021, o mesmo portal mantém o aviso de que "O ciclo da doença atualmente é silvestre, com transmissão por meio de vetor (mosquitos dos gêneros Haemagogus e Sabethes no ambiente silvestre). O último caso de febre amarela urbana foi registrado no Brasil em 1942 e todos os casos confirmados desde então decorrem do ciclo silvestre de transmissão" (SAÚDE..., 2021). Posição reforçada pelo pesquisador Henriques (2018, p. 12)), da Fiocruz, que, em Nota de Conjuntura, afirma que a febre amarela continua sendo considerada uma doença silvestre no Brasil, e que a vacina contra a febre amarela é o 
único método para evitar que "a doença volte a se urbanizar", mas que nem todos precisam receber a vacina. "Ela é essencial para quem frequenta áreas de mata ou suas proximidades. Ela não é importante para pessoas que vivem em regiões densamente edificadas, distantes de matas e têm certeza de que não vão se deslocar”.

De acordo com informações da Secretaria de Estado da Saúde do Espírito Santo (FEBRE AMARELA..., Secretaria de Estado da Saúde do ES, 2017), até 30 de março de 2017 foram confirmados 141 casos de febre amarela silvestre no estado, ou seja, com transmissão ocorrida na área rural, e 43 óbitos decorrentes, sendo imunizadas 2.645 .549 pessoas contra a febre amarela, o que representou uma cobertura vacinal de 73,94 \%, até aquela data.

Em todo o ano de 2017, foram confirmados 330 casos de febre amarela silvestre no ES, e, desse total, 100 casos evoluíram para óbito. Além disso, 3.077 .619 pessoas foram imunizadas contra a febre amarela em todo o estado, o que representou uma cobertura vacinal de $85,71 \%$ da população capixaba. Considerando o histórico de vacinação do estado desde 1994, no Espírito Santo foi vacinado um total de 3.398.144 pessoas, correspondendo a 94,97\% de cobertura vacinal, até o dia 26 de dezembro de 2017 (FEBRE AMARELA..., Secretaria de Estado da Saúde do Espírito Santo, 2018). De acordo com o Informe $\mathrm{N}^{\circ}$ 36/2017, da Secretaria de Vigilância em Saúde (BOLETIM..., 2017, p. 2), órgão do Ministério da Saúde, o Brasil vivia "o maior surto de febre amarela observado nas últimas décadas, envolvendo principalmente os estados de Minas Gerais e Espírito Santo, que apresentam os maiores números de casos confirmados".

Os dois jornais impressos capixabas, assim como qualquer veículo de imprensa, tinham liberdade e autonomia para assumir posições em relação a quaisquer temas, e transparecerem isso nos conteúdos informativos e opinativos. Reiterando o que foi frisado nos resultados e discussão, para proceder a este estudo foram levados em conta informações, dados e protocolos adotados e publicizados pelos órgãos públicos nacionais e internacionais de saúde à época sobre a febre amarela, que eram os disponíveis tanto para A Gazeta quanto para A Tribuna. Contudo, os dados epidemiológicos, que se mostraram graves, só se tornaram dados oficiais e públicos posteriormente, o que é praxe na vigilância epidemiológica em se tratando de monitoramento, confirmação e divulgação de casos de arboviroses. Então, uma primeira inferência da pesquisa é a de que a cobertura de $A G$ e $A T$ "noticiou o que viu, vacinou o que não viu", fazendo analogia a um dito popular.

Para a primeira proposição de pesquisa, a conclusão é que a cobertura teve viés 
alarmista, provocando incertezas nos moradores das áreas urbanas, principalmente da região metropolitana da Grande Vitória, contribuindo para a procura desordenada aos postos de vacinação, que registravam longas filas e tumultos para quem queria receber a vacina contra a FA. Os dois impressos capixabas apuravam, recebiam e publicavam as notificações e estatísticas de casos da febre amarela silvestre, mas, conforme verificado nas etapas quantitativa e qualitativa na Análise de Conteúdo, repercutiram sem a devida e necessária distinção para a febre amarela urbana, que permanece sem casos registrados desde 1942.

Em relação à segunda proposição de pesquisa, a conclusão é que houve predominante Conflito Discursivo entre os campos jornalístico e da saúde, e entre agentes do próprio campo da saúde, pois a construção da narrativa jornalística de $A$ Gazeta e A Tribuna, além do viés alarmista, mostrou-se em prol da vacinação em massa de toda a população do Espírito Santo, a despeito das orientações e posicionamentos da maior parte dos interlocutores da saúde, que reconheciam os cuidados preventivos de vacinação a serem tomados, mas reiteravam a não necessidade de pânico e alarmismo para procurar os postos de vacinação, especialmente para a população da Grande Vitória.

Por fim, o papel social dos dois jornais impressos capixabas nessa cobertura limitouse ao clássico mediador da informação, de mero prestador de serviço público, apenas divulgando locais e horários de vacinação nos postos de saúde e transcrevendo na gramática jornalística as orientações dos especialistas da saúde sobre sintomas, transmissão e prevenção contra a febre amarela. Não foi constatado, sob a perspectiva conceitual teórica proposta para esta pesquisa, um papel social do jornalismo de divulgador científico, de fomentador de debates acerca de políticas públicas de saúde efetivamente preventivas contra futuras manifestações epidêmicas, restringindo os espaços de fala da sociedade a relatos e fotografias sensacionalistas de dor e tragédias diante das morbidades e mortalidades dos casos de febre amarela, e, sob o viés educador/preventivo, limitando-se a reproduzir infográficos de portais de secretarias de Saúde e Ministério da Saúde. 


\section{Referências}

AVANÇO de virus. A Tribuna, Vitória, p. 5, 27 jan. 2017.

BARDIN, Laurence. Análise de conteúdo. 3. ed. Lisboa: Ed. 70, 2004.

BOLETIM epidemiológico. Secretaria de Vigilância em Saúde. Ministério da Saúde, v. 48, n. 28, 2017. Disponível em:

https://portalarquivos2.saude.gov.br/images/pdf/2017/setembro/06/2017_027.pdf. Acesso em: 28 mar. 2021.

BOURDIEU, Pierre. O poder simbólico. Lisboa: DIFEL, 1989.

BOURDIEU, Pierre. Os usos sociais da ciência. São Paulo: Editora UNESP, 2004.

CALDAS, Graça. Mídia e políticas públicas para a comunicação da ciência. In: PORTO, Cristiane de Magalhâes; BROTAS, Antonio Marcos Pereira; BORTOLIERO, Simone Terezinha. Diálogos entre ciência e divulgação científica: leituras contemporâneas. Salvador: EDUFBA, 2011, p.19-36.

CASOS suspeitos de febre amarela no Estado deixam Saúde em alerta. A Gazeta, Vitória, p. 1, 16 jan. 2017.

CASTELFRANCHI, Yurij. Por que comunicar temas de ciência e tecnologia ao público? In: MASSARANI, Luisa (org.). Jornalismo e ciência: uma perspectiva ibero-americana. Rio de Janeiro: FIOCRUZ, 2010, p.13-22.

CASTIEL, Luis David; ÁlVAREZ-DARDET DIAZ, Carlos. A saúde persecutória: os limites da responsabilidade. Rio de Janeiro: Editora FIOCRUZ, 2007.

CZERESNIA, Dina. Os sentidos da saúde e da doença. Rio de Janeiro: Editora Fiocruz, 2013.

DIAS, Kaique; CHAGAS, Katilaine, SÀ, Carla. A Gazeta, Vitória, p. 4, 25 jan. 2017.

EM ALERTA. A Gazeta, Vitória, p. 11, 13 jan. 2017.

ENTMAN, Robert Mathew. Framing: toward clarification of a fractured paradigm. Journal of Communication, v. 43, n. 4, p. 51-58, 1993.

[ENTREVISTA]. A Tribuna, Vitória, p. 2, 14 jan. 2017.

ESTADO já tem dois pacientes com suspeita de febre amarela. A Tribuna, Vitória, p. 1, 16 jan. 2017.

ESPÍRITO Santo é o Estado mais vulnerável à doença. A Gazeta, Vitória, p. 4, 21 jan. 2017.

FEBRE amarela. A Tribuna, Vitória, p. 3, 01 fev. 2017.

FEBRE amarela: Espírito Santo mantém vacinação contra a doença. Secretaria de Estado da 
Saúde do ES. 25 jan. 2018. Disponível em: https://saude.es.gov.br/Not\%C3\%ADcia/febreamarela-espirito-santo-mantem-vacinacao-contra-a-doenca. Acesso em: 28 mar. 2021.

FEBRE amarela silvestre: 94 notificações descartadas. Secretaria de Estado da Saúde do ES. 31 mar. 2017. Disponível em: https://saude.es.gov.br/Notícia/febre-amarela-silvestre-94notificacoes-descartadas. Acesso em: 28 mar. 2021.

HANSEN, Anders. Science Communication and Media. In: HOLLIMAN, R., WHITELEGG, E., SCANLON, E.; SMIDT, S.; THOMAS, J. (eds.). Investigating science communication in theinformation age: implications for public engagement and popular media. Oxford: Oxford University Press, p.105-127, 2009.

HENRIQUES, Claudio Maierovitch Pessanha. A dupla epidemia: febre amarela e desinformação. Reciis - Rev. Eletron. Comun. Inf. Inov. Saúde, v.12, n. 1, p. 9-13, jan./mar. 2018.

HOHLFELDT, Antonio; MARTINO, Luiz Claudio; FRANÇA, Vera Veiga (org.). Teorias da comunicação. Conceitos, escolas e tendências. Petrópolis: Vozes, 2001.

LERNER, Kátia. Doença, mídia e subjetividades: algumas aproximações teóricas. In: LERNER, Katia; SACRAMENTO, Igor (org). Saúde e Jornalismo: interfaces contemporâneas. 1. ed. Rio de Janeiro: Editora Fiocruz, 2014, p. 151-161. v. 1.

LERNER, Kátia. Investigando o conceito de saúde no contexto do Jornalismo: alguns desafios teórico-metodológicos. In: PESSONI, Arquimedes (org.). Comunicação, saúde e pluralidade: novos olhares e abordagens em pauta. São Caetano do Sul: USCS, 2015, p. 18720.

MALINVERNI, Claudia. Uma epizootia, duas notícias: a febre amarela como epidemia e como não epidemia. Reciis - Rev. Eletron. Comun. Inf. Inov. Saúde, Rio de Janeiro, v. 11, n. 2, abr./jun. 2017.

MENDONÇA, Maíra. A Gazeta, Vitória, p. 4, 21 jan. 2017.

OLIVEIRA, Valdir Castro de. As fabulações jornalísticas e a saúde. In: LERNER, Katia; SACRAMENTO, Igor (org.). Saúde e Jornalismo: interfaces contemporâneas. 1. ed. Rio de Janeiro: Editora Fiocruz, 2014, p. 35-60. v. 1.

PETERS, Hans Peter. A interação entre jornalistas e especialistas científicos: cooperação e conflito entre duas culturas profissionais. In: MASSARANI, Luisa; TURNEY, Jon; MOREIRA, Ildeu. Terra Incógnita: a interface entre ciência e público. Rio de Janeiro: Casa da Ciência, Museu da Vida e Vieira \& Lent, 2005, p.139-160.

RISCO de febre amarela no Espírito Santo. A Gazeta, Vitória, p. 1, 13 jan. 2017.

SAÚDE de A a Z. Ministério da Saúde. Disponível em: https://www.gov.br/saude/ptbr/assuntos/saude-de-a-a-z-1/f/febre-amarela. Acesso em: 28 mar.2021.

SURTO de febre amarela em Minas Gerais deixa Espírito Santo em alerta. A Tribuna, 
Vitória, p. 1, 14 jan. 2017.

TABAKMAN, Roxana. A saúde na mídia: medicina para jornalistas, jornalismo para médicos. São Paulo: Summus Editorial, 2013.

WAISBORD, Silvio. Cuando la salud es titular: dengue, gripe AH1N1 y ciclos "mediáticosepidemicos. Folios 23. Facultad de Comunicaciones, Universidad de Antioquia, 2010.

WOLF, Mauro. Teoria das comunicações de massa. 2. ed. São Paulo: Martins Fontes, 2005.

Submetido em 25.09.2020

Aprovado em 14.01.2021 